\title{
THE SCIENTIFIC CONGRESS IN MEXICO
}

The Seventh American Scientific Congress held in Mexico City September 8-17, 1935, under the auspices of the Department of Public Education of the Republic of Mexico, was attended by over four hundred delegates, representing nearly all the countries belonging to the Pan-American Union.

Universities and scientific societies in the United States were represented by thirty delegates, of whom the following were designated as official delegates from the United States Government (without expense to the government): President C. H. Marvin, of George Washington University, chairman; President W. W. Atwood, of Clark University; Dr. J. McK. Cattell, Editor of Science; President F. S. Harris, of Brigham Young University; Professor E. V. Huntington, of Harvard University; Mr. N. M. Judd, of the Smithsonian Institution, Mr. F. V. Scholes, of the Carnegie Institution, and Mr. W. W. Schott, second secretary of the American Embassy in Mexico City. Among the universities represented were: Harvard, Yale, Chicago, California, Leland Stanford, George Washington, Clark, Brigham Young, Kansas, Miami, Minnesota, New Mexico, Pittsburgh, and the University of Washington.

The American Mathematical Society was represented by Professor E. V. Huntington. The Mathematical Association of America had appointed Professor E. L. Dodd of the University of Texas as its representative, but he was unable to attend on account of illness in his family. The American Association for the Advancement of Science was represented by Dr. J. McK. Cattell and Dr. M. S. Vallarta.

After a welcoming reception on Sunday evening, September 8, the Congress was officially opened on September 9 by General L. Cardenas, President of the Republic of Mexico, in the recently completed and imposing Palace of Fine Arts. The scientific sessions began work immediately, under the direction of Dr. P. C. Sánchez, President of the organizing committee, and Mr. L. S. Pontón, general secretary.

There were fourteen sections of the Congress, as follows: 1. Physical and Mathematical sciences; 2. Geology; 3. Engineer- 
ing; 4. Industrial Chemistry; 5. Agriculture; 6. Biology ; 7. Medicine; 8. Hygiene; 9. Anthropology and History; 10. Social and Economic Sciences; 11. Education; 12. Bibliography; 13. Indigenous Section; and 14. Jurisprudence. The proceedings of each section, it is understood, will be published in full by the Mexican Government.

The Section of Physical and Mathematical Sciences elected as its president Dr. J. Gallo, director of the National Astronomical Observatory at Tacubaya, Mexico, and as its secretary Dr. M. S. Vallarta, Associate Professor of Physics at the Massachusetts Institute of Technology. This section held seven sessions, at which about twenty-five papers were presented. The attendance at several of these sessions was over sixty. The papers contributed by American delegates were as follows:

E. L. Dodd, $A$ survey of statistical means or averages (presented by Professor Huntington in the absence of the author).

E. V. Huntington, An elementary determination of a rigorous equation for the figure of the earth (illustrated with lantern slides).

M. S. Vallarta, $A$ theory of cosmic radiation and its experimental test.

A resolution introduced by Dr. Gallo in favor of calendar reform on the twelve-month plan known as the World Calendar was adopted. Another resolution urged a wider adoption of the metric system in the countries of the Western Hemisphere.

In a country like Mexico, with its rich natural resources and its magnificent historical treasures, it is natural that sciences like geography and archaeology should be further advanced than the more abstract science of mathematics. But it was evident from conversations with Mexican students, many of whom have studied in the United States, that post-graduate courses in pure mathematics will before long be available in Mexico. The cooperation of American mathematicians in this plan is cordially desired. It may be remarked in passing that the social and educational problems presented by the closing of the National University of Mexico for lack of funds (which occurred while the Scientific Congress was in progress) are far too complex for any foreigner to understand or discuss.

On the social side, the Mexican authorities left nothing undone for the lavish entertainment of their guests. Of particular interest to those wishing to see the actual operation of the gov- 
ernment were the excursions through the welfare colonies, model homes, and model markets, and the democratic features of the President's Reception in the National Palace on the national holiday (September 15). The all-day trips to the famous ruins at San Juan Teotihuacán, the caves at Cacahuamilpa, and the floating gardens at Xochimilco were notable examples of the generous hospitality with which the Congress was constantly surrounded. The high development of a national culture in the realm of music was evident on every hand, and the delightful and invigorating climate of Mexico City added an important element to the success of a notable gathering.

E. V. Huntington 